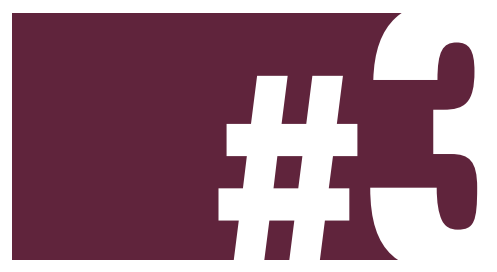

ESPECIAL DIVERSIDADE E GESTÃO

\title{
ORIENTAÇÃO SEXUAL E TRABALHO
}

MESMO AS EMPRESAS QUE ADOTAM POLÍTICAS DE DIVERSIDADE E RESPEITO À DIFERENÇA TÊM SEUS AMBIENTES DE TRABALHO CARACTERIZADOS PELO HETEROCENTRISMO E PELA HOMOFOBIA. A VALORIZAÇÃO DA DIVERSIDADE EXISTE NOS DISCURSOS, MAS NÃO NAS PRÁTICAS EMPRESARIAIS

HÉLIO ARTHUR REIS IRIGARAY, professor da FGV-EBAPE, helio.irigaray@fgv.br

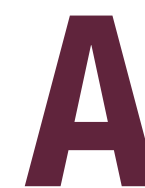
o longo dos anos, as empresas têm sido administradas e estudadas como se fossem entidades assépticas, nas quais os indivíduos convivem de forma funcional e neutra em prol de objetivos econômicos comuns. Consequentemente, os discursos, políticas e práticas organizacionais foram construídos negligenciando diferenças e silenciando minorias. Mas como continuar a fazê-lo, se a força de trabalho tem se tornado cada vez mais diversificada? O espaço corporativo passou a ser compartilhado e disputado por indivíduos de diferentes gêneros, etnias, gerações, religiões, e também orientações sexuais. Neste artigo, o foco são os homens e mulheres homo e bissexuais.

\section{DISCURSO HOMOGENEIZADOR}

Em decorrência de seu ideal de neutralidade e tecnicismo, as organizações adotam uma perspectiva de homogeneidade no seu cotidiano. Lidam com os indivíduos que nelas trabalham como se suas diferenças pudessem ser ocultadas sem maiores 
problemas sob o manto da formalidade, dos rituais e processos organizacionais, e das posições hierárquicas. $\mathrm{Na}$ prática, isso significa pressupor que os empregados separam suas características e interesses pessoais dos profissionais, subjugando sua dimensão de indivíduo ao "bem comum" organizacional.

Essa visão, no entanto, é limitada, ao ignorar que existem racionalidades concorrentes na organização e também ao supor que os indivíduos são capazes de fazer essa clivagem entre quem são como homens e mulheres e quem são como profissionais. Na prática, a intolerância à diversidade de orientações sexuais resulta no comprometimento da dignidade dos indivíduos, aumenta seu nível de estresse e prejudica, no limite, o desempenho da própria empresa.

\section{HOMOFOBIA}

\section{E HETERONORMATIVIDADE}

Entender esses dois conceitos é fundamental quando se discute a gestão da diversidade no ambiente de trabalho. Ao longo dos séculos, a homossexualidade foi vista como crime, pecado e patologia, respectivamente pelo Estado, pela Igreja e pela ciência. Não raramente se observam atitudes de repulsa por homossexuais e o desejo consciente de puni-los, o



A discriminação se esconde sob a máscara do humor e da informalidade

que se denomina homofobia. Há ainda a homofobia incrustada, que se refere à aceitação ou adoção inconsciente de sentimentos e atitudes negativos. Os próprios indivíduos gays compartilham desse tipo de sentimento (homofobia egodistônica) por autoafirmação, por medo de serem tirados do armário, ou mesmo pela dificuldade em lidarem com sua própria orientação sexual. $\mathrm{Na}$ sociedade brasileira, a homofobia jaz na construção da masculinidade na infância e permeia a vida cultural, por exemplo, nas representações de homossexuais em letras de músicas, na literatura e no cinema.

Já a heteronormatividade refere-se à crença na superioridade da orientação heterossexual e à consequente exclusão, proposital ou não, de indi- víduos não heterossexuais de políticas públicas e organizacionais, eventos ou atividades. Menos explícita que a homofobia e, por isso mesmo, mais vil, a heteronormatividade nega manifestações culturais não heterossexuais. De fato, a sociedade em geral sente certo desconforto com a presença e manifestação de qualquer comportamento não heterossexual, o que explica, por exemplo, a exclusão de gays e lésbicas de anúncios na mídia; a premissa de que homossexuais são fúteis ou devassos e que, por isso, não precisam casar e não querem ter filhos; e a inclusão da homossexualidade como assunto obrigatório quando se discute a pandemia de aids, mas não quando o tópico são direitos humanos, por exemplo. 


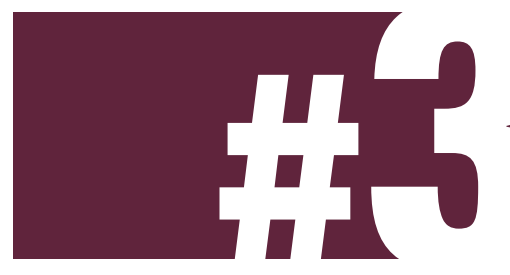

\section{LIDANDO (MAL) COM A DIFERENÇA.}

A diversidade no ambiente de trabalho não é um desafio apenas para os indivíduos, mas também para as organizações. De um lado, ambientes com maior heterogeneidade - de culturas, religiões, etnias, visões de mundo costumam ser mais criativos, pois facilitam a troca de informações sobre experiências, valores e atitudes, e a apreensão de novas abordagens. Por outro lado, essa mesma heterogeneidade pode também resultar em conflitos e problemas de comunicação, na redução de integração e contatos sociais, e no enfraquecimento dos laços de lealdade entre os colegas de trabalho e destes com a organização em si.

Essa realidade tem imposto às empresas a necessidade de elaborar políticas organizacionais explícitas para lidar com a diversidade. Mas, nesse particular, a experiência tem mostrado que as pessoas são muito mais propensas a aceitar as diferenças étnicas, sociais e de gênero do que a diversidade de orientações sexuais, e essa realidade se reflete no cotidiano organizacional.

Mesmo nas empresas que adotam



políticas de diversidade, os discursos empresariais encontram dificuldades de ser efetivamente praticados, devido a preconceitos arraigados, por parte dos próprios empregados, a certo nível de permissividade gerencial e à ausência de senso coletivo de diversidade. Homo, bi e heterossexuais demonstram preconceito e atitudes discriminatórias entre si, do que se pode depreender a dificuldade de implementação de políticas de estímulo à diversidade e à inclusão a partir da própria ótica dos empregados, que não respeitam as diferenças uns dos outros. No caso dos gerentes, apesar de as políticas deixarem claro que possuem objetivos específicos nesse sentido, há manifestações de preconceito, explícitas ou veladas, que minam a percepção dos empregados sobre a efetividade de tais políticas. A valorização da diversidade, assim, existe nos discursos, mas não nas práticas empresariais.

\section{AUTOEXCLUSÃO}

A invisibilidade de que se queixam os homoafetivos tem diversas causas, dentre as quais a interiorização do estigma. Esses segmentos "invisíveis" podem ter sido alvo de um nível tal de preconceito que preferem se esconder, recorrendo ao silenciamento sobre discriminações sofridas e à 
autoexclusão de temas que possam ressaltar as diferenças. Na prática, esses indivíduos revelam-se politicamente desarticulados nas empresas e, ainda que conscientes de seus direitos, demonstram medo de eventuais represálias, o que ressalta a distância entre o discurso e a prática das políticas de diversidade.

Além disso, o processo discriminatório pode ser atenuado por conta de outros traços psicográficos, como, por exemplo, o maior poder aquisitivo, a pele branca ou a conformidade com padrões estéticos dominantes na sociedade.

Assim como os gays, as lésbicas percebem-se discriminadas no ambiente de trabalho, seja explicitamente ou de forma implícita, por exemplo, quando o tratamento diferenciado se esconde sob a máscara do humor e da informalidade. Da mesma forma que seus equivalentes masculinos, as mulheres homossexuais costumam sentir-se mais confortáveis quando a empresa possui e efetivamente implementa políticas de respeito à diversidade; quando seus colegas de trabalho se mostram abertos às diferenças e não fazem comentários jocosos ou piadas; e, finalmente, quando trabalham com outras pessoas, sobretudos chefes, que compartilhem da mesma orientação sexual.

As pessoas são mais propensas a aceitar as diferenças étnicas. sociais ou de gênero do que a diversidade sexual nas

\section{organizações}

\section{QUANDO SE ESCONDER É IMPOSSÍVEL}

Se tanto os homossexuais masculinos quanto as femininas têm a alternativa de ocultar sua orientação sexual, essa possibilidade não está ao alcance das travestis e transexuais. Ao mesmo tempo, travestis e transexuais não se beneficiam daqueles fatores atenuantes do processo discriminatório, muitas vezes ao alcance de gays e lésbicas: via de regra, têm baixa educação formal, baixa renda, ausência ou instabilidade de emprego, saúde precária, más condições de moradia, etc.

A violência e a miséria a que esses indivíduos estão expostos no Brasil costumam ser decisivas para selar o seu destino: a grande maioria se prostitui, e os poucos que conseguem entrar para o mercado de trabalho formal têm seu horizonte limitado a funções subalternas. Mesmo os poucos inseridos no mundo do trabalho são vítimas de agressões, violência e intolerância por parte de colegas, inclusive naquelas empresas que afirmam possuir políticas de diversidade e respeito à diferença.

\section{DESAFIO DE TODOS}

Reconhecer a existência de múltiplas identidades e orientações sexuais resulta em implicações para a academia, empresas e sociedade como um todo. No que diz respeito à academia, é papel dos pesquisadores buscar compreender melhor a realidade dos indivíduos cujas vozes são silenciadas pelos discursos organizacionais.

No que tange às empresas, há a necessidade urgente de melhor compreensão por parte dos administradores, de modo que possam formular políticas organizacionais capazes de conduzir à melhoria da qualidade de vida, condições de trabalho e dignidade de todos os empregados, e, mais importante, colocá-las efetivamente em prática. Em relação à sociedade, espera-se que seja responsável pelo reconhecimento da cidadania de todos os seus segmentos - algo que, ao contrário do que pregam muitos discursos institucionalizados, ainda está longe de ser alcançado. 